\title{
Operational problems of large power diesel engines combusting biofuels, considered together with assessment of their operation
}

\author{
Jerzy Girtler, Prof. \\ Zbigniew Korczewski, Assoc. prof. \\ Gdansk University of Technology \\ Jacek Mańczak, M. Sc. \\ H. CEGIELSKI - Poznan S. A.
}

\begin{abstract}
In this paper the problem is discussed of supplying high power diesel engines with biofuels in the aspect of consequences which occurr during their operation. Attention was paid to advantages and difficulties associated with application of biofuels to self-ignition engines. A relevant research problem was characterized and research targets were proposed to make it possible to most favourably shape energy merits of the engines. Special attention was given to wear process of such engines and their failures resulting from application of biofuels. The following problems were also considered: calcium carbonate sedimentation, closing graphite platelets in structure of cylider bearing surface and surface defects of piston rings made of aluminium bronze. It was demonstrated that to assess operation of the engines is possible under the assumption that in a valuating approach their operation can be compared to a physical quantity represented numerically and measured with the use of the joule*sec unit. Conclusions resulting from the domestic and foreign investigations on power and reliability of such engines were also presented.
\end{abstract}

Keywords: biofuel; operation; engine about automatic ignition; expendable

\section{INTRODUCTION}

In $21^{\text {st }}$ century world economy has been dominated from its beginning by two problems: warfare against global warming-up and energy shortage, mainly electric one, and threat of running- low natural energy raw material resources, closely associated with the first. The themes are very closely connected to each other. Limitations associated with the global climate warming-up, consisting a. o. in reduction of emission limits of noxious gases such as NOx, SOx and first of all $\mathrm{CO}_{2}$ have resulted in searching for alternative, pure and renewable energy sources [12]. However in applying renewable energy sources the today demand on electric power was to be taken into account.

Until now in lower developed countries (e. g.Poland) electric power demand has been mainly covered by conventional coal-fired power plants operating on the basis of steam-turbine-driven electric generators. Unfortunately, the electric power stations appear to be the largest emitters of carbon dioxide, and their efficiency is rather not high.

An alternative to the conventional electric power stations, as far as large power blocks are concerned, seems to be nuclear power industry, however after the Czarnobyl disaster its development has been effectively slowed down, at least in Eastern Europe.

Development of nuclear power industry is associated with a high initial cost of electric power plants. The highest outlays should be incurred during the building of nuclear reactor and before its putting into operation. Its investment cycle is also relatively long. Therefore it should be stated that power industry of the kind is rather intended for reach countries and its impact could be really felt at the end of the second decade.

Pure energy sources are represented obviously by water - power plants as well as wind - power plants flourishing now in Europe. Experience gained at the run of century has showed that the winddriven generator itself does not solve the problem in question as lack of wind is capable of leading to ,black-out" and consequently paralysing life of the entire country as it was the case of Denmark and Holland. Presently we know that the wind electric power plants are to be bufferred at least in $50 \%$ by another power source being in a hot stand-by state. To this end, electric generators driven either by four-stroke self-ignition engines or medium- or large- power gas turbines, are commonly used.

The self-ignition engine since its very beginning has been used for driving the electric generating sets, however it has practically been auxiliary, emergency, small power generators installed on objects requiring continuous supply or located far from electric networks, as well as generators on board of ships. Their output does not generally exceed $1 \mathrm{MW}$.

Contemporary power industry surely expects solutions of electric generating sets of a much greater output - up to $20 \mathrm{MW}$ and more - and available from one unit. The most modern diesel engines both 
four-stroke and two-stroke ones, designed on the basis of main engines intended for propelling large ships, are capable of coping with such tasks. Morover, a high efficiency of electric generating set driven by diesel engine supports attractivity of such solution.

The large-power, two-stroke crosshead engine has an advantage which cannot be overestimated: it is relatively insensitive to fuel of a low quality, because of its specific design solution and adjustment to combusting heavy oils, of a rather not high quality, usually. This is especially important today in the situation of runing-low resources of natural liquid fuels and searching for alternative ones. For this reason research investigations on application of alternative fuels of vegetable origin, so called biofuels to self-ignition engines have been conducted for many years by domestic and foreign scientific research institutions ${ }^{1}$.

\section{GENERAL ASSESSMENT OF RESULTS OF THE INVESTIGATIONS HAVE BEEN CONDUCTED SO FAR}

Research work on applicability of biofuels to supplying selfignition engines, of small power in particular, has been carried out by various scientific and scientific-industrial research centres. The activity has been triggered off due to growing awareness that $[1,2,3,8]$ :

- crude oil resources are lower and lower,

- it is urgently necessary to limit emission of noxious compounds contained in exhaust gases,

- bio-fuels are bio-degradeable.

It resulted in that biofuels which are methyl esters (sometimes ethyls) of fatty acids (FAME - Fatty Acid Metyl Esters) have achieved greater and greater importance in worldwide power industry. In Poland the methyl esters of fatty acids of rape oil (EMKOR) are mainly used. In this case their biodegradeability due to which they may be considered pro-ecological fuels, is of a special importance. The feature of biofuels has really directed interest of leading diesel engine producers to the fuels; it may be hence expected that investigations on consequences of application of such fuels will be continued.

The conducted research $[1,13,15,16]$ deals mainly with: the methyl ester of fatty acids of rape oil, soybean oil, sunflower oil, their mixtures with diesel oil, and the methyl ester of fatty acids of palm oil, just recently. Investigations on application of animal fat waste as an alternative fuel are also carried out. It brings an additional advantage due to reduction of waste utilization cost.

The vegetable fuels and their mixtures with diesel oil are characterized by a higher viscosity as compared with that of diesel oil, that makes engine starting-up process much more difficult. However engine starting-up features can be improved by providing heaters for biofuels characterized by high viscosity. The heating-up of such fuels can reduce their viscosity down to a level comparable to that of diesel oil. As results also from the invstigations, there are still important problems concerning the following items: excessively long combustion, reduced ignition lag, long injection process, slowed down evaporation of fuel droplets and worser fuel spraying quality. Moreover the fuels show high aggressiveness (chemical activity of highly acid reaction) against fuel piping and apparatus, that makes it necessary to apply special materials (stainless steel, sealings etc). Also, they do not have good lubricating features for precision pairs of injection pumps and injectors, moreover they should have a low impact on change of physical and chemical features of lubricating oils in case of a leakage of the fuels to the oils resulting from loss of tightness of injection apparatus. For the above mentioned reasons further resarch is necessary to reach the following aims [8]:

- improvement of starting-up features of engines from cold state, especially at low ambient temperatures,

- determination of impact of vegetable fuels and their derivatives on: fuel piping corrosion, wear of injection pumps, injectors and the tribological system consisted of piston, rings and cylinder liner (resulting from friction and corrosion wear, sedimentation of lakes and calcium carbonate, cracks in piston heads and cylinder liners etc) as well as wear of crankshaft bearings,

- determination of impact of vegetable fuels and their derivatives, in case of their leaking to lubricating oils during operation of engines, on physical and chemical features of the oils.

The investigations have been performed so far, on applicability of the vegetable oils and their esters in question as alternative fuels for diesel engines, have yielded promising results.

As a matter of fact from results of investigations on combustion of biofuels in engines the following was concluded: a decrease of their output, increase of specific fuel consumption (especially at higher engine speeds) and a decrease of efficiency, but simultaneously - decrease of exhaust smokiness, as compared with the case of diesel oil combustion in the engines. Exhaust gas temperature of biofuel-fed engine is lower as compared with that produced during diesel oil combustion.

As stated from the performed investigations, the supplying of diesel engines with biofuels results in:

- greater sedimentation of contaminations on surfaces of combustion chamber elements as well as on surfaces of spraying nozzles of injectors,

- worsened operational parameters of the engines in question (lower output, higher specific fuel oil consumption, lower efficiency), sometimes higher smokiness of exhaust gas at lower rotational speeds of the engines,

- increased emisssion of noxiuos exhaust-gas components such as: $\mathrm{CO}$ and $\mathrm{C}_{\mathrm{n}} \mathrm{H}_{\mathrm{m}}$, resulting in a lower content of $\mathrm{CO}_{2}$, but also lower content of $\mathrm{NO}_{\mathrm{x}}$ in exhaust gas at higher engine loads.

The higher content of hydrocarbons $\left(\mathrm{C}_{\mathrm{n}} \mathrm{H}_{\mathrm{m}}\right)$ in exhaust gas of the engines combusting biofuels results mainly from that the flame ionization detectors of $\mathrm{C}_{\mathrm{n}} \mathrm{H}_{\mathrm{m}}$ analyzer do not seperate, from the hydrocarbons, aldehydes which are in a much greater amount in biofuels than in diesel oils.

Along with growing engine wear the differentiation of emission of the above mentioned compounds increases. When analyzing the presented research results it should be observed that they are promising as compared with the results obtained from investigations of gas and steam turbines used in electric power stations. The quantative data given in Fig. 1 and 2 and in Tab. 1 support the statement.

As illustrated by the presented data, in spite of the very promising prospects of the application of self-ignition engines to driving the electric generating sets it should be however

Already in 1900 Rudolf Diesel anticipating that in the future crude oil and coal tar may be in shortage, presented, during Paris exhibition, an engine combusting arachis oil. For many years such fuels have not been used as the fuel obtained from crude oil was (and is still) less expensive 
stated that the results obtained during the investigations have been performed so far on combustion processes in biofuel-fed engines, could not fully reveal their operational merits, as they have dealt only with energy aspects. No complex investigations concerning durability of main tribological units of the engines have been conducted with accounting for technical diagnostics, endoscopy based in particular. Proposals of such investigations are presented in this paper.

$\mathrm{CO}_{2}[\mathrm{~g} / \mathrm{kWh}]$

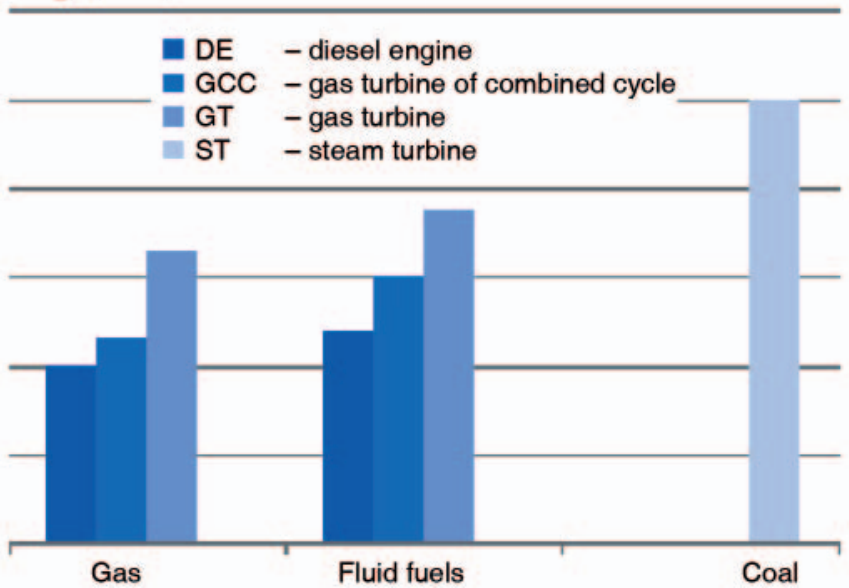

Fig. 1. Specific emission of $\mathrm{CO}_{2}$ contained in exhaust gases for various types of electric power stations and mineral fuels [14]

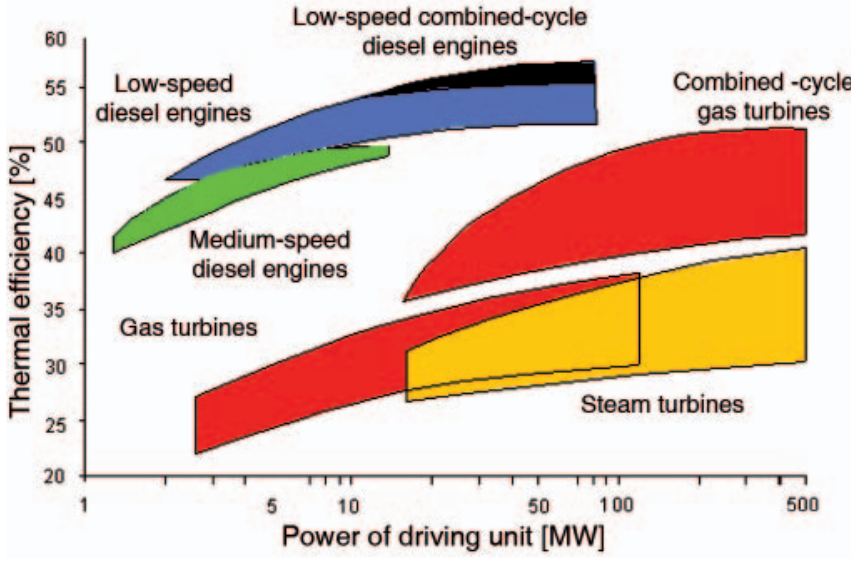

Fig. 2. Comparison of efficiency of typical driving units used in electric power stations [14]
Summing up, further development of drives based on selfignition engines should be expected in power industry, and the crucial aspect deciding on reaching the success will be their reliability and reliability of electric power station as a whole.

\section{PROBLEM OF WEAR OF BIOFUEL-FED ENGINES AND THEIR TESTS}

\section{Initial remarks}

The promising results of the investigations associated with determination of energy merits of biofuels proposed for selfignition engines, have made that also research on intensity of degradation process of structures of such engines have been undertaken in order to determine a guaranteed time to failure of their particular constructional units. The results of diagnostic tests performed by MAN Diesel Co, have been obtained so far, showed that the energy parameters of „bio-engine” are kept in the range of contractual values, but values of the structural parameters of its working space change significantly due to calcium carbonate contamination - Fig. 3 [15, 16]. From the performed microscopic tests of a cylinder liner it was additionally concluded that the closing of graphite platelets in its cristallic structure took place. (Fig. 4), that may within a short time result in growing rate of wear of cylinder bearing surface - and consequently - worsening engine performance and efficiency of realized heat-and-fluid-flow processes [15, 16]. Many defects of sliding coating (aluminium bronze) of piston sealing rings of cylinder systems (Fig. 5) confirm the observation.

\section{Formation of calcium carbonate sediments on surfaces of combustion chamber elements}

During a routine overhaul of internal spaces of one of MAN Diesel biofuel - fed engines a large amount of light-beige contaminations (,chalk-like” hard sediments) were found on piston head surface as well as cylinder head from the side of combustion chamber, in all cylinder systems of the engine. Similar sediments were also found in internal spaces of the waste-heat boiler [15]. As preliminarily stated the cause of its occurence was an accumulated excess of non-used (noncombusted) additions to lubricating oil, a.o. detergent, in the form of acid calcium carbonate $\mathrm{Ca}\left(\mathrm{HCO}_{3}\right)_{2}$ which, in high

Tab. 1. Comparison of features of selected technological methods for electric power production [14]

\begin{tabular}{|c|c|c|c|c|c|c|c|}
\hline Technology & $\begin{array}{c}\text { Size of } \\
\text { units }\end{array}$ & $\begin{array}{c}\text { Investment } \\
\text { period }\end{array}$ & $\begin{array}{c}\text { Initial } \\
\text { cost/kW }\end{array}$ & $\begin{array}{c}\text { Operational } \\
\text { cost }\end{array}$ & Fuel price & $\begin{array}{c}\mathbf{C O}_{2} \\
\text { emission }\end{array}$ & $\begin{array}{c}\text { Regulation } \\
\text { risk }\end{array}$ \\
\hline Piston engines & small & very short & low & low & high & low & low \\
\hline Coal & large & long & high & medium & medium & high & high \\
\hline $\begin{array}{c}\text { Gas turbine - } \\
\text { combined cycle }\end{array}$ & medium & short & low & low & high & medium & low \\
\hline Nuclear & very large & long & high & medium & low & null & high \\
\hline Hydro & large & long & $\begin{array}{c}\text { very } \\
\text { high }\end{array}$ & very low & null & null & high \\
\hline Wind & small & short & high & very low & null & null & medium \\
\hline Fuel cell & small & very short & $\begin{array}{c}\text { very } \\
\text { high }\end{array}$ & medium & high & medium & low \\
\hline Photovoltaic & very large & very short & $\begin{array}{c}\text { very } \\
\text { high }\end{array}$ & very low & null & null & low \\
\hline
\end{tabular}



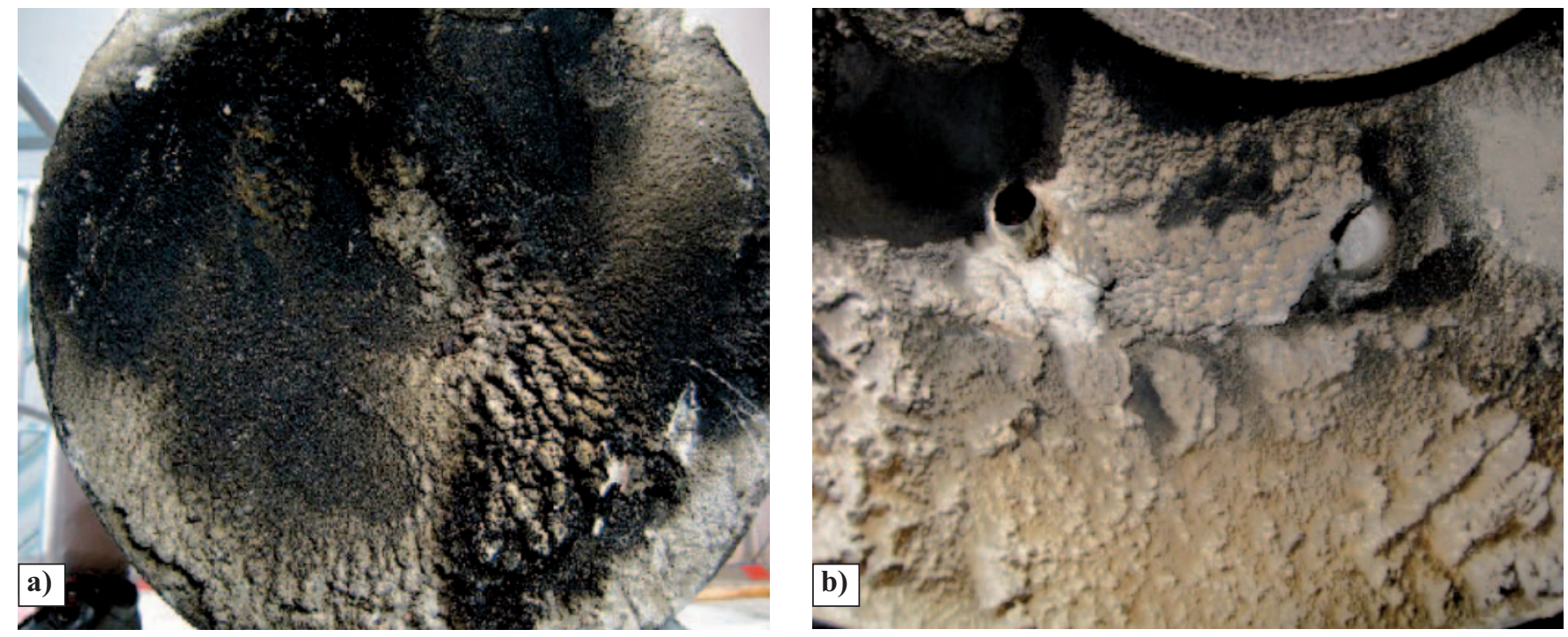

Fig. 3. View of cylinder space of the engine working on a biofuel produced on the basis of crude (not processed)palm oil. a) Calcium carbonate $\left(\mathrm{CaCO}_{3}\right)$ layer sedimented on piston head.

b) Contamination layer sedimented on the head from the side of combustion chamber in the vicinity of outlet valve and fuel injector
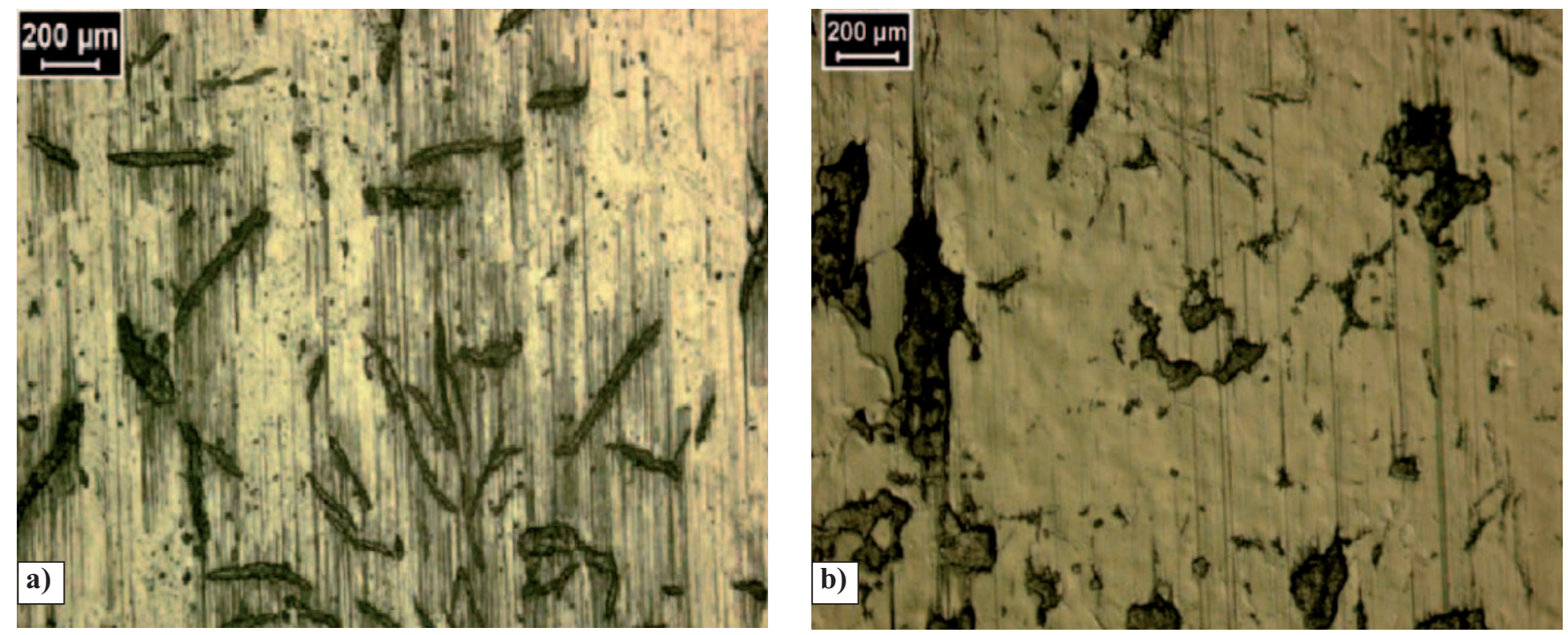

Fig. 4. Enlarged view of cylinder bearing surface of the engine working on a biofuel produced on the basis of crude (not processed)palm oil. a) Cylinder bearing surface - opened graphite platelets of good tribological qualities.

b) Cylinder bearing surface - partly closed graphite platelets of worser tribological qualities
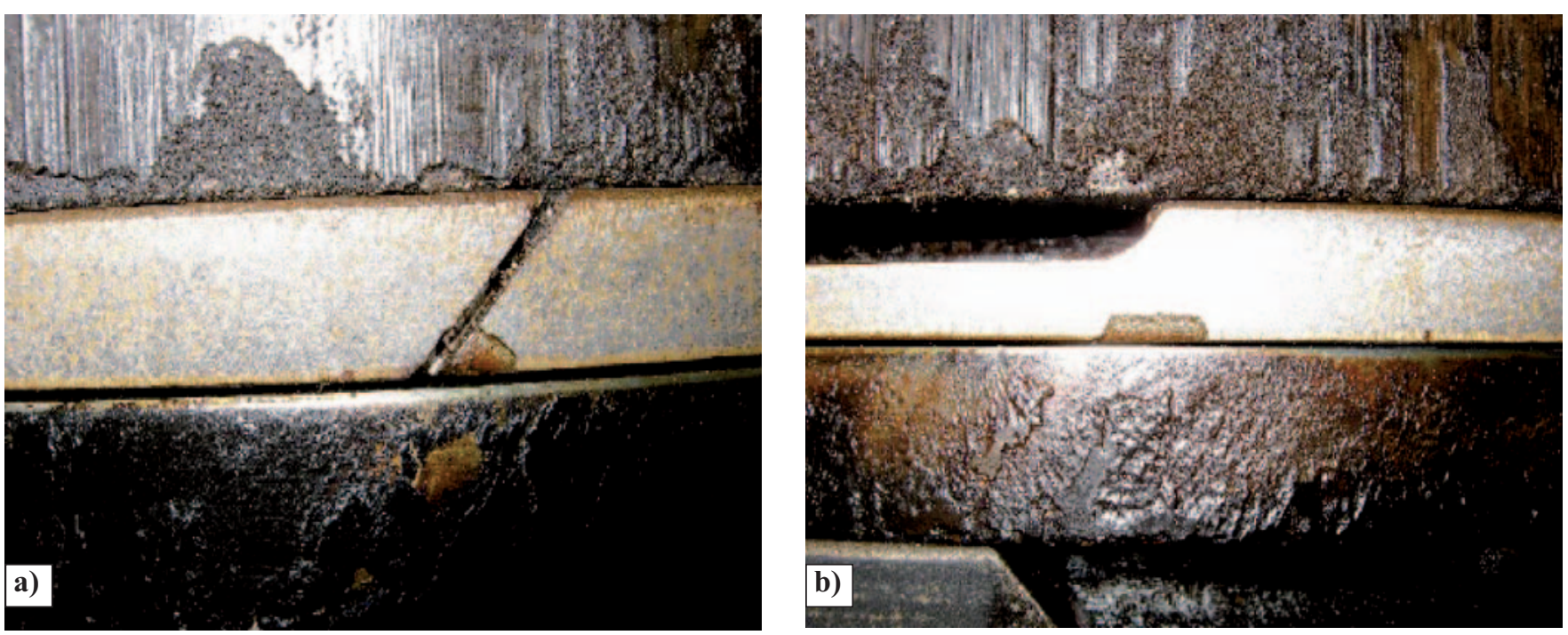

Fig. 5. Ring part of piston - the engine working on a biofuel produced on the basis of crude (not processed)palm oil. a) Sliding surface of piston sealing ring - defects of aluminium bronze layer in the vicinity of piston-ring joint.

b) Sliding surface of piston sealing ring - defects of aluminium bronze layer 
temperatures, releases calcium carbonate $\mathrm{CaCO}_{3}$, water vapour $\mathrm{H}_{2} \mathrm{O}$ w and carbon dioxide $\mathrm{CO}_{2}$ :

$$
\mathrm{Ca}\left(\mathrm{HCO}_{3}\right)_{2} \rightarrow \mathrm{CaCO}_{3}+\mathrm{H}_{2} \mathrm{O}+\mathrm{CO}_{2}
$$

As deemed, it was caused by mutual interaction (an inappropriate combination) of base number of lubricating oil (TBN40) and a supplied fuel not containing sulfur. On the other side there is no commercial production of a lubricating oil of a base number smaller than TBN40. As separated hard particles of calcium carbonate sediments disturbe oil film as well as stable work of piston rings, they contribute in accelerated friction and errosion wear process of the cylinder bearing surface. Knowing that an inceased charge of cylinder oil could not improve the situation, but on the contrary it could accelerate rate of $\mathrm{CaCO}_{3}$ sedimenation, one decided to limit the charge of lubricating oil (supplied to cylinder bearing surface through two lubricators) to the value of $1.05 \mathrm{~g} / \mathrm{kWh}$. According to MAN Diesel Co statement, such value should be generally determined on the basis of the relation of $\mathrm{F} \times \mathrm{S} \%$, where the empirical coefficient $\mathrm{F}$ takes values from 0.26 to 0.34 (and $\mathrm{S} \%$ - percentage content of sulfur in fuel oil). Positive results of the lubrication at the lower coefficient have been demonstrated by tests and such values are recommended today. Generally, it can be concluded that the cylinder oil charge should not be taken lower than $0.8 \mathrm{~g} / \mathrm{kWh}$. From the producer's experience have been gained so far it results that CL-DX405 oil of a reduced base number TBN40, reduced acid calcium carbonate content, at maintained high washing capacity, is the best adjusted cylinder oil for biofuel -fed engines (as well as for engines fed with fuel oil having sulfur content smaller than $1.5 \%$ ).

One may expect very soon that producers of lubricating means for low-speed engines will undertake intensive research on a new composition of lubricating oil of a TBN value close to $20 \mathrm{mgKOH} / \mathrm{g}$. It results not only from demands put by biofuels but first of all from new legal regulations dealing with sea environment protection (Anex VI to Marpol 73/78 Convention) in which some navigation regions were specified (a.o. the Baltic Sea, selected regions of the North Sea, region of La Manche Channel etc) where only use of fuel oils of sulfur content smaller than $1.5 \%$, with its target value lowered to $0.5 \%$, is permitted.
Because of the so small amount of lubricating oil applied to cylinder liner, it must be very precisely spread over the entire cylinder bearing surface in order to ensure a high quality of all realized functions of lubricating oil, namely:

- limitation of adhesive wear by eliminating direct metal-tometal contact of faying surfaces of piston rings and cylinder bearing surface,

- limitation of corrosion wear by neutralizing acid combusion products, first of all sulfuric acid, in the form of calcium carbonate,

- ensurance of stable (durable) oil film between piston ring and cylinder bearing surface,

- limitation of sedimenting rate of contaminations in engine working spaces (combustion chambers),

- ensurance of proper sealing the rings in piston grooves.

Therefore a perspective, effective way to further control of oil consumption for lubrication of cylinder liners is the supplying of oil in an amount proportional to engine load (i.e. fuel oil charge delivered to cylinders) and proportional to percentage content of sulfur in fuel oil. In older solutions the functions have been realized by using a mechanical system connected with engine load indicator, today - by specialty electronic systems, e.g. the Alfa-lubrication system for MAN Diesel engines - Fig. 6, intended for controlling value of cylinder oil charge.

However two basic conditions must be fulfilled:

1. the cylinder oil charge cannot be smaller than a value which limits tribological wear of friction surfaces to a minimum,

2. amounts of alkalic anticorrosive additions and detergents should be limited to a minimum necessary to neutralize formed acids and keep piston rings clean (ensurance of a sufficient washing capacity).

In the case of the engine fed with sulfur - free biofuel the cylinder oil charge should be proportional to engine's load with taking into account measurement results of contamination of the lubrication oil by Fe-particles. This makes it possible to estimate rate of wear of cylinder bearing surface and on this basis to correct an optimum charge from lubricator. As determined from service measurements of wear of cylinder

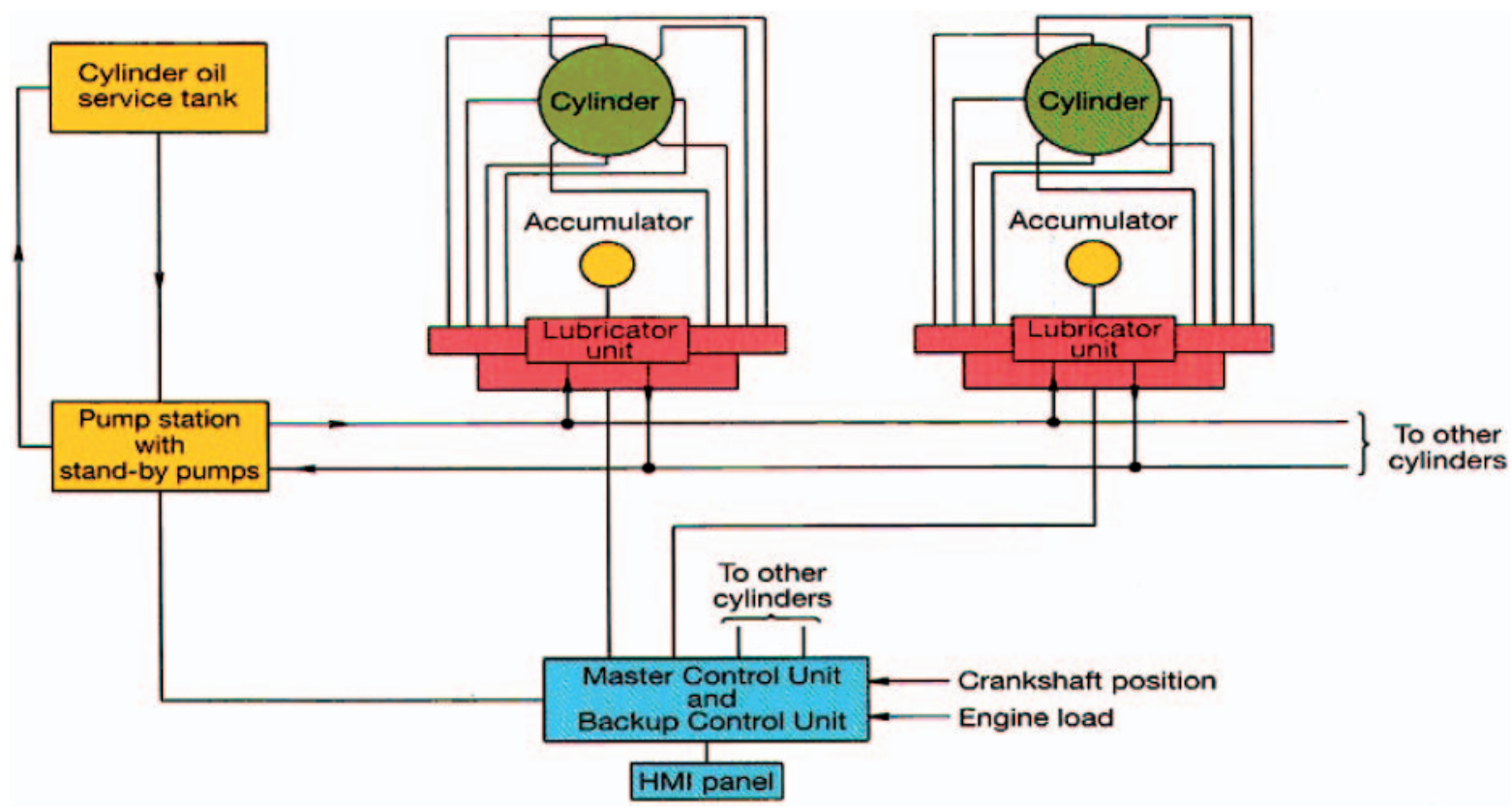

Fig. 6. Schematic diagram of the Alfa-lubrication system for controlling cylinder oil charge in MAN Diesel engines [14] 
liners of MAN Diesel two-stroke engines, the mean rate of wear of cylinder liner was not greater than $0,1 \mathrm{~mm} / 1000 \mathrm{~h}[15,16]$ (the data concerned the heavy-oil-fed engines).

\section{Closing graphite platelets in outer layer of cylinder bearing surface}

As concluded from results of diagnostic tests have been conducted so far on large power diesel engines, lubrication conditions can be improved to a certain extent by allowing controlled corrosion process of cylinder bearing surface to happen [15]. Local corrosion cells occurring in the form of microscopic ,pocketlets" filled with lubricating oil support hydrodynamical lubrication process. Complete elimination of erosion and corrosion processes may lead to a loss of honing structure and polishing effect of cylinder bearing surface (Fig. 7).

It usually results in closing the graphite platelets within cristallic structure of outer layer of cylinder bearing surface, that disturbes the building process of essential oil film. Consequently, it leads to increasing consumption of lubricating oil, scuffing piston rings in cylinder liner, and even seizing effects in PRC (Piston-Rings-Cylinder) system.

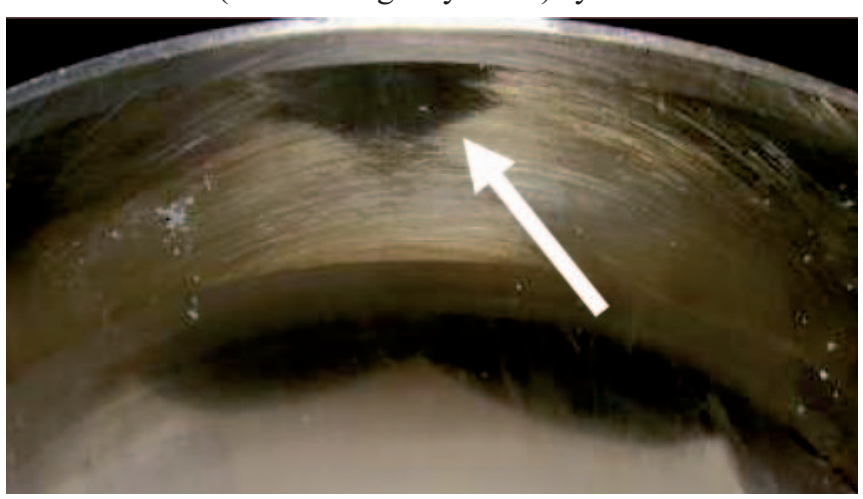

Fig. 7. Polished (mirror) cylinder bearing surface

\section{Wear-affected operation of engines}

Operation of diesel engines consists in the transforming and transferring of supplied energy $[4,5]$. It becomes worser and worser along with growing wear of the engines. To assess their operation is hence deemed necessary.

Doing so, one should take into account that the transformation of energy in the form of heat or work, which occurs in working spaces of every diesel engine, should be such as to make the work to be done within a given time, as large as possible, or to do the work as fast as possible. In practice it is also important to release, during combustion process, as much heat as possible, and to reduce waste heat to a possible minimum. If due to wear of the engine to obtain such most favourable energy transformation is not possible, then the operation of the engine is considered incorrect and it is assumed that the engine is then in the state of partial serviceability $[4,5]$.

As the operation of such engines consists in the transformation of the energy E into the form of the work L and heat Q it can be hence generally interpreted as follows:

$$
\mathrm{D}=\int_{0}^{\mathrm{t}} \mathrm{E}(\tau) \mathrm{d} \tau
$$

where:

D - engine operation

E - transformed (obtained) energy which makes realization of the task $\mathrm{Z}$ possible,

$\mathrm{t}-$ duration time of transforming (using) the energy $\mathrm{E}$
In the most general case, $\mathrm{E}(\tau)$ may be considered the internal combustion gas energy which makes it possible to do the useful work $\mathrm{L}_{\mathrm{e}}(\tau)$ by the engine. The energy is obviously obtained from the chemical energy contained in air-fuel mixture during fuel combustion in working spaces of every engine. Transformation of the chemical energy during operation of the engine results in the thermal and mechanical loading of the engine, that consequently results in growing wear of the engine and energy losses associated with the wear [4, 10, 11]. To conclude about serviceability of a particular engine is possible after calculating value of its operation from Eq. (2), which, in the proposed interpretation, is equated to a physical quantity having the measure unit called joule-second. In order to determine the area of operation (D) it is obviously necessary to know a functional relation of energy and time, i.e. $E=f(t)$. The so-understood operation determined by Eq. (2), can be presented in the coordinate frame ,E- $\mathrm{t}$ ”, hence also in the form of a diagram called diagram of operation $[4,5]$. In view of that $D=f(E, t)$ the operation of devices can be presented in the coordinate frame ,D-E-t” $[4,5]$.

In the case of an arbitrary self-ignition engine, the transformation of the chemical energy (contained in air-fuel mixture produced in combustion chambers) into thermal one and then mechanical one, makes it possible to generate the crankshaft torque $\left(\mathrm{M}_{\mathrm{o}}\right)$ at a given rotational speed (n) [5]. Therefore the engine operation described by Eq. (2) may be interpreted as the energy transformation into the form of the useful work $\mathrm{L}_{\mathrm{e}}$ and expressed by the formula:

$$
\mathrm{D}_{\mathrm{L}_{\mathrm{e}}}=\int_{0}^{\mathrm{t}} \mathrm{L}_{\mathrm{e}}(\tau) \mathrm{d} \tau=2 \pi \int_{0}^{\mathrm{t}} \mathrm{n}(\tau) \mathrm{M}_{\mathrm{o}}(\tau) \tau \mathrm{d} \tau
$$

As results from the presented considerations, it is reasonable to analyze not only the work $\mathrm{L}$ but also the operation (D) of such engines, in this case understood as the energy transformation in the engine, which leads to achieving a necessary amount of the useful work $\left(\mathrm{L}_{\mathrm{e}}\right)$ within a definite time (t). It makes it possible to determine if the possible engine operation $\left(D_{M}\right)$ in given conditions is at least equal to the demanded operation $\left(D_{W}\right)$ necessary for realization of a given task $\mathrm{Z}$.

The task $(Z)$ to realization of which the combustion engine is adjusted in the phase of its designing and manufacturing, can be realized only when the following inequality is satisfied:

$$
\mathrm{D}_{\mathrm{M}} \geq \mathrm{D}_{\mathrm{W}}
$$

i.e. when:

$$
\mathrm{t}_{\mathrm{M}} \geq \mathrm{t}_{\mathrm{W}}, \text { and simultaneously } \mathrm{E}_{\mathrm{M}} \geq \mathrm{E}_{\mathrm{W}}
$$

where:

$\mathrm{t}_{\mathrm{M}}-$ possible operational time of engine

$t_{w}-$ demanded operational time of engine

$\mathrm{E}_{\mathrm{M}}$ - energy which can be transformed by engine

$\mathrm{E}_{\mathrm{W}}$ - energy demanded (necessary) to realize the task Z (energy which must be transformed to realize the task Z).

It means that by analyzing energy merits of combustion engines in a general sense with the use of Eq. (2), one can consider serviceability of the engines in the following variants, acounting for their wearing:

$$
\left.\begin{array}{l}
\mathrm{t}_{\mathrm{M}}=\mathrm{t}_{\mathrm{W}} \text {, and simultaneously } \mathrm{E}_{\mathrm{M}}=\mathrm{E}_{\mathrm{W}} \\
\mathrm{t}_{\mathrm{M}}=\mathrm{t}_{\mathrm{W}} \text {, and simultaneously } \mathrm{E}_{\mathrm{M}}>\mathrm{E}_{\mathrm{W}} \\
\mathrm{t}_{\mathrm{M}}>\mathrm{t}_{\mathrm{W}} \text {, and simultaneously } \mathrm{E}_{\mathrm{M}}=\mathrm{E}_{\mathrm{W}} \\
\mathrm{t}_{\mathrm{M}}>\mathrm{t}_{\mathrm{W}} \text {, and simultaneously } \mathrm{E}_{\mathrm{M}}>\mathrm{E}_{\mathrm{W}}
\end{array}\right\}
$$


In the particular case when in assessing the engine operation it is important the definite work $\mathrm{L}_{\mathrm{e}}$ to be done by the engine, then the relation (5) should be presented in the following form:

$$
\left.\begin{array}{l}
\mathrm{t}_{\mathrm{M}}=\mathrm{t}_{\mathrm{W}}, \text { and simultaneously } \mathrm{L}_{\mathrm{eM}}=\mathrm{L}_{\mathrm{eW}} \\
\mathrm{t}_{\mathrm{M}}=\mathrm{t}_{\mathrm{W}}, \text { and simultaneously } \mathrm{L}_{\mathrm{eM}}>\mathrm{L}_{\mathrm{eW}} \\
\mathrm{t}_{\mathrm{M}}>\mathrm{t}_{\mathrm{W}} \text {, and simultaneously } \mathrm{L}_{\mathrm{eM}}=\mathrm{L}_{\mathrm{eW}} \\
\mathrm{t}_{\mathrm{M}}>\mathrm{t}_{\mathrm{W}} \text {, and simultaneously } \mathrm{L}_{\mathrm{eM}}>\mathrm{L}_{\mathrm{eW}}
\end{array}\right\}
$$

where:

$\mathrm{t}_{\mathrm{M}}-$ possible operational time of engine

$t_{w}-$ demanded operational time of engine

$\mathrm{L}_{\mathrm{eM}}$ - useful work which can be done by engine

$\mathrm{L}_{\mathrm{eW}}$ - useful work which is demanded (necessary) to realize the task $Z$ (useful work which must be done to realize the task Z).

As a rule it is important to do the useful work $\mathrm{L}_{\mathrm{e}}$ within a definite time. Then to assess the engine operation it is necessary to know how fast the work can be done. A physical quantity which contains such information is the effective power $\mathrm{N}_{\mathrm{e}}$ as it determines, in case of any machine, how fast a given work will be (or can be) done within a given time. Hence in the case of assessing the engine operation when it is important the engine to develop a definite power $\left(\mathrm{N}_{\mathrm{e}}\right)$, the relation (6) can be presented as follows:

$$
\left.\begin{array}{l}
\mathrm{t}_{\mathrm{M}}=\mathrm{t}_{\mathrm{W}} \text {, and simultaneously } \mathrm{N}_{\mathrm{eM}}=\mathrm{N}_{\mathrm{eW}} \\
\mathrm{t}_{\mathrm{M}}=\mathrm{t}_{\mathrm{W}} \text {, and simultaneously } \mathrm{N}_{\mathrm{eM}}>\mathrm{N}_{\mathrm{eW}} \\
\mathrm{t}_{\mathrm{M}}>\mathrm{t}_{\mathrm{W}} \text {, and simultaneously } \mathrm{N}_{\mathrm{eM}}=\mathrm{N}_{\mathrm{eW}} \\
\mathrm{t}_{\mathrm{M}}>\mathrm{t}_{\mathrm{W}} \text {, and simultaneously } \mathrm{N}_{\mathrm{eM}}>\mathrm{N}_{\mathrm{eW}}
\end{array}\right\}
$$

where:

$\mathrm{t}_{\mathrm{M}} \quad$ - possible operational time of engine

$t_{w}-$ demanded operational time of engine

$\mathrm{N}_{\mathrm{eM}}$ - effective power which can be developed by engine

$\mathrm{N}_{\mathrm{eW}}$ - effective power demanded (necessary) to realize the task $\mathrm{Z}$ (effective power which must be generated to realize the task $Z$ ).

In the case when the inequality is satisfied:

$$
\mathrm{D}_{\mathrm{M}}<\mathrm{DW}
$$

then it should be concluded that the engine in question is damaged and not capable of realizing the assumed task $\mathrm{Z}$.

In the case of considering the situations (6) and (7) the inequality (8) should be expressed as follows:

$$
\mathrm{L}_{\mathrm{eM}}<\mathrm{L}_{\mathrm{eW}} \text { or } \mathrm{N}_{\mathrm{eM}}<\mathrm{N}_{\mathrm{eW}}
$$

Therefore in order to determine if a given engine is serviceable to realize a given task, its operation should be identified $[10,11]$. As the operation depends on a degree of engine's wear, its identification must be connected with identification of engine's wear, e.g. in a way presented above in this paper.

\section{RECAPITULATION. FINAL REMARKS AND CONCLUSIONS}

Features of diesel oil and considered alternative fuels are very different. Therefore it should be expected that self-ignition engines must be subjected to a special adjustment, or even modification, depending on a kind of fuel delivered to them. To adjust the engine fuel system to features of vegetable fuel oils of and their mixtures with diesel oil is necessary because of their high viscosity as compared with that of diesel oil. One of the possible ways of decreasing the viscosity of biofuels and improving their spraying quality is to apply a heating-up system to the fuel oils, that makes it necessary to supplement the fuel system, not only with the fuel - oil heater but also a viscometer for measuring fuel oil viscosity as well as a viscostat - for controlling flow of heating medium through the heater and maintaining this way fuel oil viscosity on a required level.

Biodegradability of the vegetable fuel oils is a very positive quality. However to be capable of serving as fully useful fuel oils they should:

- ensure similar energy qualities as compared with diesel oil,

- do not cause an excessive wear of engine and consequently reduce life time of engine,

- be a source of only low quantities of environmentally noxious substances $\left(\mathrm{CO}_{2}\right)$,

- ensure a low specific fuel oil consumption by engine,

- facilitate recycling of raw and packing materials associated with their production.

Choice of an alternative fuel oil obtained from fatty acid esters of vegetable oils and being their mixture with diesel oil should be based on research results dealing not only with energy and ecology aspects but also with durability and reliability of crucial structural units of the engines, namely: injection, crankshaft and piston-cylinder systems.

In order to be able to select a kind of biofuel, out of those have been tested so far, additional tests on durability of biofuelfed self-ignition engines should be performed.

For application of biofuels it is necessary to achieve credible information concerning not only the energy aspects and potential pollution hazard to the environment by noxious substances, but also the developing of wear processes within the engine, i.e. its reliability and durability. In order to achieve a comprehensive knowledge dealing with the problems technical diagnostics should be used $[6,9]$.

Features of diesel oil and the considered alternative fuel oils influence in a different way not only energy merits of selfignition engines but also their wear and operation.

The operation of engines may be understood in different ways. In this paper it is understood as the process of generating, by the engines, the energy $\mathrm{E}$ within a definite time $\mathrm{t}$. It has been equated to a physical quantity expressed by a numerical value measured by the unit called joule-second $[\mathrm{J} \cdot \mathrm{sec}]$. The so-understood operation becomes worser and worser along with progressing wear of such engines. It means that value of the operation within a given time decreases as a result of lowering amount of energy generated by the engine. The so-interpreted operation depends on a technical state of the engine characterized simultaneously by the energy transformed by it and the energy generating time.

The engine operation presented in this version is of such virtue that it can be investigated by performing measurements of quantities which characterize energy and can be expressed numerically as a value measured by the joule-second unit $[\mathrm{J} \cdot \mathrm{sec}]$ (Eq. 2 and 3), as well as presented in a graphical form as an area of operation.

Depending on practical needs and possibile assessment of operation of the engines, their operation can be valuated as a result of consideration of the useful work (6) which can be done by the engine, or the effective power (7) which can be developed by the engine. As engine's power contains information on how fast the work can be done, hence the effective engine power can be considered an energy rate of its operation (engine operation rate). 
The so-interpreted operation, in spite of that it was formulated with a view of self-ignition engines, may deal also with spark-iginition ones. Similar interpretation of operation can be applied also to gas turbines and other power devices.

\section{BIBLIOGRAPHY}

1. Adamczyk A., Lotko W.: Application of mixtures composed of alternative fuels and diesel oil to direct-injection engines (in Polish). AUTO-Technika Motoryzacyjna (CAR - Motorization Engineering), No. 11, 1990

2. Heywood J.B.: Internal Combustion Engine Fundamentals. McGraw-Hill Book Company, Series in Mechanical Engineering, New York 1988

3. Höglund P.G., Ydstedt A.: Reduced Air Pollution and Fuel Consumption with Preheated Car Engines. Urban Transport and the Environment for the $21^{\text {st }}$ Century, International Conference, Lisbon 1998

4. Girtler J.: Possibility of valuation of operation of marine diesel engines. Journal of Polish CIMAC, Vol. 4, No. 1, 2009

5. Girtler J.: Energetic aspect of diesel engine operation. Silniki Spalinowe (Combustion Engines), No. 2, (2009).

6. Korczewski Z. Endoscopy of ship engines (in Polish). Polish Naval Academy, Gdynia 2008

7. Lindl B., Schmotz H.G.: Cold Start Equipment for Diesel Direct Injection Engines. SAE Technical Paper 1999-01-1244.

8. Lotko W.: Supplying combustion engines with alternative fuels (in Polish). ITE, Radom 1995

9. Polanowski S.: Assessing diagnostic applicability of heat release characteristics determined on the basis of ship engine indicator diagram. Polish Maritime Research. No. 3(61) Vol. 16, 2009

10.Rudnicki J.: On making operational decisions with taking into account value of operation applied to ship main propulsion engine as an example. Journal of Polish CIMAC, Vol. 4, No.1, 2009
11 Rudnicki J.: Assessment of operation of energy system of serial reliability structure on the example of ship main propulsion system. Journal of Polish CIMAC, Vol. 3, No. 2, 2008

12.Svensson B.: IMO's MARPOL Annex VI will affect engine lubrication. Diesel \& Gas Turbine Worldwide, May 2006

13.Szlachta Z.: Supplying high-pressure engines with rape oil fuels (in Polish). WKiE

(Transport and Communication Publishers), Warsaw 2002

14.Wędzik A.: Combined electric power generating systems (in Polish). Elektroenergetyka (Electric power engineering), No.06/ $05 / 02$

15.Woodyard D.: Cylinder oil challenges and choices. Marine Propulsion \& Auxiliary Machinery. 12/2009,01/2010

16. Woodyard D.: Marine diesel engines and gas turbines. $8^{\text {th }}$ Edition, Elsevier Ltd, 2004

\section{CONTACT WITH THE AUTHORS}

Jerzy Girtler, Prof.

Zbigniew Korczewski, Assoc. Prof. Faculty of Ocean Engineering and Ship Technology

Gdansk University of Technology Narutowicza 11/12 80-952 Gdansk, POLAND

tel.: (+48 58) 347-24-30; fax: (+48 58) 347-19-81 e-mail: jgirtl@pg.gda.pl e-mail: zbigniew korczewski@pg.gda.pl Jacek Mańczak, M. Sc.

H. CEGIELSKI - Poznan S. A. 